\title{
The Search for School Safety and the African American Homeschooling Experience ${ }^{1}$
}

\author{
Garvey Musumunu ${ }^{2}$ \\ Montgomery County Community College \\ garvey49@hotmail.com
}

Ama Mazama

Temple University

ama_mazama@hotmail.com

\begin{abstract}
Interest in homeschooling has increased over the last decade, as what was once perceived as a marginal development has turned into a significant phenomenon. There has been, in recent years, a noticeable surge in African American involvement in the homeschooling movement as well. However, there continues to be a general paucity of research on the motivations of homeschooling Black parents. It is the purpose of this essay (1) to present empirical evidence regarding African American motivations for homeschooling; and (2) more specifically, to explore how parental concerns for safety are leading African American families to homeschooling. These concerns, the authors contend, bring to the fore a series of disturbing circumstances and preoccupations that are specific to African Americans.
\end{abstract}

\section{Introduction}

Academic interest in homeschooling has increased over the last decade, as what was once perceived as a marginal development, has, in fact, turned into a significant and growing phenomenon. Indeed, it is estimated that over 2 million children are being homeschooled today in the United States, as opposed to 300,000 in 1990, thus indicating a dramatic increase over a relatively short period of time (Gathier, 2007; Ray, 2010). As a matter of fact, homeschooling, which grew by 74\% between 1999 and 2007 (Grady \& Bielick, 2010), appears to be the fastestgrowing form of education in the United States today. While White students still represent about $75 \%$ of all homeschooled children, there has been a noticeable surge in African American involvement in the homeschool movement as well (Coleman, 2003). However, there continues to be a general paucity of research on the motivations of homeschooling African American parents, as the common and implicit assumption seems to be that African Americans' disengagement from the school system is dictated by reasons quite similar to those cited by European Americans, such as quality of education or religious beliefs, just to name a few (Taylor, 2005).

Yet, the very unique experiences of African Americans in this society should be cause for caution as attested by the vast literature chronicling the impact of exposure to violence and

\footnotetext{
${ }^{1}$ Funding for this research was provided by a small grant from the Spencer Foundation (\#201000072)

${ }^{2}$ Formerly, Garvey Lundy

Journal of Contemporary Issues in Education, 2014, 9(2), pp. 24-38

ISSN 1718-4770 () 2014 University of Alberta

http://ejournals.library.ualberta.ca/index.php/JCIE
} 
school performance (Patton, Woolley \& Hong 2012). It is the purpose of this essay to present the motivational forces leading African Americans to homeschool, and more specifically, to explore how parental concern for safety has led African American families to opt out of traditional brick-and-mortar schooling for homeschooling. While discontent with traditional schooling has been cited by many other groups as the motivation for homeschooling, the concern of African American parents for the safety of their children, this paper contends, brings to the fore a series of disturbing circumstances and preoccupations that are specific to African Americans.

\section{The African American Experience in Homeschooling}

Numerous attempts have been made to explore the motivations for homeschooling among American parents (e.g., Collom, 2005; Green \& Hoover-Dempsey, 2007). What clearly transpires from a review of this literature is that American homeschoolers do not lend themselves to easy and neat classifications. At best, we arrive at categories which must be broad enough to encompass the multitude of experiences that they claim to capture. Yet, their very broadness undermines their usefulness (Isenberg, 2007). At the heart of this difficulty lies the fact that the homeschooling population's heterogeneity has considerably increased over the past decades. Thus, categories such as the "pedagogical" and "ideological" ones which were once proposed by Van Galen (1991), and which managed to capture the two main groups of homeschoolers in the 1980s, namely the libertarian political left and the religious right, must be considerably enlarged to include parents who homeschool because of their dissatisfaction with public and private schools, family needs, and academic concerns, for example. Furthermore, such categories should arguably also be able to reflect the motivations of racially under-represented groups, which have been glaringly absent from most of the literature mentioned above. As a matter of fact, only a few studies have dealt more specifically with African American homeschooling families (e.g., McDowell, Sanchez, \& Jones, 2000). Yet, it is important to recognize, as cogently argued by McDowell et al. (2000, p. 130), that "Clearly, the decision to homeschool for African American parents contains a great many critical and diverse elements that are simply not a factor for Euro-Americans." Our own study on the motivations of African American homeschooling parents is offered as an attempt to fill the conspicuous absence of the African American voice in scholarly discussions about motivations for homeschooling.

\section{The School as an Unsafe Space}

Many parents harbor the notion that schools are unsafe. Parental fears are fueled by their own experiences, but also by national and local media coverage of violence in schools. The most recent case is the widely reported massacre in Newtown, Connecticut, where, on December 14, 2012 a lone gunman shot twenty first graders and six adults before taking his own life at an elementary school. The sheer magnitude of the carnage, and the senseless loss of so many young lives, made this event a national tragedy. However, often outside the media gaze, instances of violence are common in urban areas like Philadelphia, Chicago, or Oakland, California where many schools must grapple with alarming levels of violence. At the end of the 2012 academic year, for example, 24 students were fatally shot in the Chicago public school system, only four fewer than the previous year. The overall shooting toll for Chicago was a staggering 319 - the highest in four years and a nearly 22 percent increase from the previous school year (AhmedUllah, 2012). In 1999, Philadelphia placed metal detectors in all of its high schools at a cost of 
$\$ 5$ million, and more recently the city has been debating whether to equip its elementary schools with metal detectors as well (Haney, 1999; Leach, 2013).

Public discussions on school safety, however, tend to conceive the latter in the narrow sense of physical safety. This is probably because physical safety is more tangible, and lends itself to more immediate public outcry and action. Albeit important, though, it is critical to realize that physical safety is only one dimension of school safety. When it comes to creating a safe space for children to learn and thrive, the notion of safety must be broadened to include the various factors that contribute to a rich and secure learning environment. We agree with Manvell (2012) that what makes a school unsafe should be understood as a continuum of acts and attitudes that negatively affect how students feel and learn in the classroom. Lost in the debate on school violence are the equally important emotional, intellectual, and cultural assaults students may endure in school. Safety, thus, is a continuum that includes physical, emotional, intellectual, and cultural components.

\section{Physical Safety and its impact on learning}

Some have argued that claims of school physical violence increase are greatly exaggerated, as a result of unwarranted media hype (e.g. Cornell, 2011). However, recent national statistics on school violence and safety do give reason for pause. In 2006, for example, there were 29 violent crimes at school per 1,000 students. These included rape, both sexual and aggravated assault, and robbery. More recent statistics reveal that, in 2010, students aged 12 through 18 were victims of about 828,000 crimes at school (Robers, Zhang, \& Truman, 2012). These numbers undeniably attest to the physical insecurity that many students confront as they enter school in the morning. More importantly, in such a context, learning unavoidably takes a back seat to the more pressing issue of preserving one's physical integrity. Generally speaking, school violence has been linked with lower school grades, lower self-esteem and shorter hours studying at home, while being attacked at school is predictive of students' misbehavior (Fitzpatrick \& Boldizar, 1993).

Thus, the dangers that children must contend with while in school are a justified source of parental alarm. This is even truer for African Americans parents as they must often navigate an urban landscape characterized by dwindling funding for public schools as well as the lingering and daily effects of historical and contemporary racial discrimination (Kozol, 2005). That safety concerns should play a significant role in the African American decision to homeschool should therefore not be a surprise since African American families and communities often experience the ill-effects of urban decline to a greater degree than others (Wilson, 1996).

\section{Emotional Safety}

Emotional safety is a more abstract type of safety, but its significance cannot be underestimated since there are clear connections between feelings and learning outcomes (Janson $\&$ King, 2006). In effect, researchers posit classroom emotional climate (CEC) as a central factor in determining student success and engagement. Classrooms high in CEC are characterized, among other things, by student-teacher relationships that are warm, caring, and nurturing. Teachers in such classrooms are aware of the emotional needs of their students and respond in age-appropriate ways that foster self-expression and insure a level of emotional 
security that is beneficial to the students' psychological and academic well-being (Reyes et al. 2012). There is accumulated evidence in support of CEC as crucial to student safety and success. Students are more likely to succeed in school when their basic longing for relatedness, competence, and autonomy are met (Connell \& Wellborn, 1991). Overall, students in emotionally supportive classrooms report greater interest, enjoyment, and overall engagement (Sylwester, 1994).

\section{Intellectual and Cultural Safety}

The third component of a safe school is intellectual and cultural safety. Indeed, intellectual exploration and education are believed to be synonymous. One can assume that the major project of an educational institution is an intellectual one, where learning occurs and the exploration of new ideas is a given. Sadly, however, the accumulated data on American schooling belie these assumptions and bring into question the actual intellectual safety of schools.

An intellectually safe school does not tolerate a climate where teachers belittle students' different approach to learning, or where children and/or teacher laugh when the wrong answer is given. An intellectually safe school is a learning space where students are allowed to make mistakes and raise questions, but more importantly, it is a school that values ideas and exploration, and the freedom to take unpopular positions (Merrow, 2004).

The pattern of inordinate referral of black students to special education (Skiba et al, 2008) suggests that intellectual security may well be far beyond the reach of that group. Indeed, African American students' ways of learning and expressing themselves seem to be often misunderstood by teachers who are unable to adjust their teaching style to their students' cultural background (Ladson-Billings, 1995). In the end, this failure gravely interferes with black students' academic progress, and intellectual and cultural safety. In effect, if intellectual and cultural safety means creating a space where students are free to express ideas and display their different ways of learning, then it is fair to conclude that American schools are failing African American children.

More subtly, the school curriculum also contributes to the intellectual and cultural insecurity experienced by many African American students. American schools largely continue to focus on Europe, the supposedly "natural" norm for all. European culture and thought are implicitly presented as universal, and Europe as the only place from which great ideas and discoveries originated (Mazama, 2003). Such an experience is far from ideal for African American students, whose culture and history are rendered largely invisible and insignificant.

\section{The African American Quest for School Safety}

African American parents are obviously not the only group confronted with the increased lack of school safety. However, the challenge presented by school violence, in all its forms, is compounded by past and present-day racism and the inordinate material, psychological, and social challenges that it has created, thus making African American students particularly vulnerable to it (Ozer, 2005).

Given this state of affairs, it is hardly surprising that increasingly large numbers of African American parents, frustrated with schools whose safety has been seriously and 
consistently questioned, and with a system bent on treating their children still as second-class citizens, choose to educate them at home in order to provide them with a safer alternative.

\section{Research Designs and Data}

In order to capture the voice and agency of African American homeschoolers, we conducted 74 interviews across a wide geographical area, stretching along the Mid and South Atlantic, and the Midwest during the spring and summer of 2010 (See Table 1). Indeed, the largest pool of subjects came from Chicago and its surrounding suburbs (29.7 percent), followed by the metropolitan areas of Philadelphia (25.7 percent), Washington, D.C. (17.6 percent), New York (10.8 percent), and Atlanta (8.1 percent).

Table 1: Place of interviews

\begin{tabular}{lc}
\hline Chicago Metropolitan Area [Chicago Land] & $29.7 \%$ \\
Philadelphia Metropolitan area & 25.7 \\
Washington, D.C. Metropolitan area & 17.6 \\
New York City Metropolitan area & 10.8 \\
Atlanta & 8.1 \\
Columbia and Florence, South Carolina & 6.7 \\
Bridgeport, Delaware & 1.3 \\
\hline Note. $(\mathrm{N}=74)$ &
\end{tabular}

A snowball sampling procedure and active recruitment from local and national homeschooling associations accounted for a majority of respondents. The interviews consisted of two parts: a survey which sought demographic and background data for each homeschooling family. This was followed by a semi-structured, open-ended interview with the participating parent, where issues touched upon in the survey were further explored and elaborated upon by parents. Over eighty percent of the interviews were conducted with one parent - usually the mother $(\mathrm{N}=60)$ - representing the homeschooling family. The interviews ranged from roughly one and a half hours to two hours in length, and were analyzed using a three-step sequential coding process (open coding, axial coding, and selective coding) commonly referred to as grounded theory approach (Corbin \& Strauss, 2008).

The data analysis was conducted separately by the two authors. We open coded each transcript three times, each time with a different focus: (1) parental motivation for homeschooling, (2) child centered experiences leading to homeschooling, and (3) daily issues of African American homeschooling. We then met to discuss our findings and to identify areas of agreement and disagreement. Following a series of meetings, we then used the constant comparative method to explore emerging themes, common categories, and subcategories. In other words, we sought connections amongst the various emergent categories, which in turn became the basis for the emergent theory (Corbin \& Strauss, 2008). In ensure credibility, we met independently with a separate research assistant to discuss the emergent theory and expound on and clarify the selected themes. Upon completion of this process, we came together again for peer debriefing to further explain the initial theory and ensure that our theory was grounded in the data. We believe theoretical saturation was achieved upon completion of this process.

In producing the emergent themes, steps were taken to triangulate the data. The authors kept extensive journals of the research process, making observational notes of interviews, 
setting, and interaction, which on several occasion placed us as participant observers of homeschooling events. In addition, three informal focus groups were conducted with homeschooling parents, whereby we kept separate notes, which were later cross checked during debriefing (Golafshani, 2003).

The information presented in this study, however, is largely culled from the surveys and interviews. Table 2 considers the demographic characteristics of the subjects interviewed. As can be seen there is little variation in the ethnicity of black respondents interviewed. The majority of our respondents self-identified as native born African Americans, with only a few self-identifying as foreign-born or racially mixed. In terms of family description, the average family consists of 3.2 children and most were brought up in a two parent household (91 percent).

Table 2: Indicators of respondents' demographic background

\begin{tabular}{lc} 
Ethnic/Racial & \\
\hline Black/African American & $92.7 \%$ \\
Caribbean & 2.9 \\
African & 1.4 \\
Mixed race & 1.4 \\
Hispanic/Latino & 1.4 \\
Immigrant origin & \\
\hline U.S. born & 95.6 \\
$\quad$ Born abroad & 4.3 \\
Children characteristics & \\
Average number in household & 3.2 \\
Younger than 18 & 59.8 \\
Aged 18 or older & 21.9 \\
H.S. graduate & 12.9 \\
Aged 25 or older & 2.2 \\
College graduate & 3.1 \\
\hline
\end{tabular}

Note. $(\mathrm{N}=71)$

In terms of education, over 80 percent of the mothers and over 60 percent of the fathers have an undergraduate college degree or more. These figures are significantly higher than the national trend of only 19.4 percent of blacks with a Bachelor's College degree or more in 2010 (Aud et al., 2011). These figures aside, a substantial number of homeschooling households have parents with no college degree. For example, almost 20 percent of mothers and close to 40 percent of fathers do not possess a college degree.

Table 3 provides a general socioeconomic profile of our homeschooling parents. Overall, they are quite educated, with over 80 percent of the mothers and over 60 percent of the fathers having an undergraduate college degree or more. These figures are significantly higher than the national trend of only 19.4 percent of blacks with a Bachelor's College degree or more in 2010 (Aud et al., 2011). This suggests substantial human capital on the part of our homeschooling parents (Becker, 1964). These well-educated parents aside, our figures do suggest a bimodal trend that ought not to be ignored. In effect, a substantial number of homeschooling households have parents with no college degree. Although this trend is higher among fathers - who for various reasons are not as involved in homeschooling instruction as mothers - our data suggest 
that almost 20 percent of mothers and close to 40 percent of fathers do not possess a college degree.

Table 3: Indicators of respondents' socioeconomic background

Mother's highest level of schooling

Some high school

$0 \%$

High school graduate

1.4

Some college

17.4

College graduate

37.7

Some postgraduate

14.5

Graduate or professional degree

29.0

Father's highest level of schooling

Some high school

1.5

High school graduate

7.5

Some college

27.5

College graduate

37.3

Some postgraduate

2.9

Graduate or professional degree

22.4

Household income

$4,000-24,999$

15.6

25,000-34,999

12.5

$35,000-49,999$

10.9

$50,000-74,999$

18.7

$75,000-99,999$

17.2

100,000 - or more

25.0

Note. $(\mathrm{N}=71)$

Regarding household income, our data reveal broad representation across the income spectrum with a slight increase at the high end. A quarter of our subjects are in households with an income of $\$ 100,000$ or more, and over 60 percent report an income of $\$ 50,000$ or more. These figures leave, however, a substantial portion of our subjects with an income less than $\$ 50,000$ a year. According to national labor statistics, the poverty line for a family of five with three children is $\$ 26,023$. With this number as a baseline, we can ascertain that 15.6 percent of our subjects are living under the poverty line and an additional 12.5 percent hover near the poverty line.

\section{Findings}

The open-ended interviews dealt more specifically with African American parental motivations for homeschooling. Parents were asked directly, "What made you decide to homeschool?" Most respondents were quick to provide a response to this question - a question which in most cases had already been answered in the course of the interview. To insure completeness and some level of uniformity, a list of possible reasons was then read to each 
respondent, in which case respondents were free to select one or more reasons aligned with their motivation or provide an option that was not on our list.

In response to our query most parents offered a series of motives, and were rarely motivated by a single factor. As seen in Table 4, among the many reasons given, a concern with the quality of education provided in brick and mortar schools was most often mentioned, with 25 percent of respondents citing it as their first reason for homeschooling. This finding is consistent with previous research, and indeed consistent with the history of homeschooling in America (Gathier, 2007). But unlike other research on homeschooling, and unique to the African American experience, the second most mentioned motivating factor for homeschooling was a concern with racism, with about 24 percent of our respondents citing it as a motivation. African American parents' inspiration to homeschool their children was often couched as a desire to protect one's child from possible racist actions or, as is often the case, as a reaction to an egregious racist incident when their children attended school. In previous articles we dealt specifically with the issue of quality of education and racism as motivators (Authors, 2012). Not to be overlooked in our responses are the 7.9 percent of respondents who cite safety concerns as their motivating force for homeschooling. These parents, understandably, define safety concerns in the narrow sense of physical safety and their attempt to escape the physical violence that they find prevalent in brick and mortar schools. Among the more subtle themes or subcategories to emerge in our analysis are the more abstract forms of school safety - emotional and intellectual that are outlined in our literature review.

Table 4: Reasons for Homeschooling

\begin{tabular}{ll} 
Quality of Education & $25.0 \%$ \\
Racism & 23.9 \\
Family Bonds & 14.8 \\
Religious & 9.5 \\
Safety Concerns & 7.9 \\
Financial Constraints & 4.2 \\
Moral - nonreligious & 4.2 \\
Special Needs & 3.4 \\
Other & 7.6 \\
\hline
\end{tabular}

Note. $(\mathrm{N}=71)$

In many interviews, issues of intellectual and emotional safety, as well as physical safety, are expressed as a fight against institutional and individual racism, or dissatisfaction with the quality of education. We have chosen to address more specifically the issue of school safety here for several reasons: (1) with our broadened definition of school safety it became apparent that the latter is a major motivation for African American homeschooling parents; (2) given the recent publicity surrounding school violence, we felt it was important to shed light on how a group of African American parents dealing with this issue have acted to protect their children.

\section{Coming to Terms with School as a Dangerous Place for Black Children}

Many of the parents we interviewed were obviously aware of, and concerned about the physical integrity of children while in school: drugs, gangs, bullying, and sexual assault were 
mentioned as presenting real and daily threats to students on school premises. Karan, mother of five, living in Brooklyn expressed the concerns of many about security this way:

... Safety concerns, definitely I have safety concerns. I have safety concerns for the boys as well as the girls. The boys are, there's a rise in gang activity and drugs and it's just not safe. The girls, you know, I, I've heard this and I've seen a lot of different things in terms of sexuality in the schools, of girls getting raped and things like that.

Tanya, a mother of three, in Philadelphia, acknowledges that bullying prompted her to educate her son at home:

With my son, he had a lot of issues with bullying. He was being picked on, I would say at least since first grade. That really had an impact on him. He wasn't safe at school. I had to pull him out.

Moreover, being or feeling physically unsafe often leads to emotional distress. Thus, physical safety generates considerable emotional difficulties, as this statement by one mother, Clara, in Chicago, makes it clear:

Here in this area, which is sad, your child's physical and emotional wellbeing is at stake if you send your child to school in this area. It is at stake, because if a child is under attack, then he cannot feel well, he cannot feel like being in school and learning anything, and if anyone says any different they're not being honest. We're not facing the problem."

Furthermore, school administrators often seemed reluctant or incapable to address this poignant question of violence. Michelle, in Philadelphia, recalls her astonishment when she went to the principal of the white private school attended by her son to complain about his being bullied: she was told that "bullying was part of the school experience," and that her son "should learn to live with it." The issue became so severe that Michelle's son became depressed, thus leading to the decision to educate him at home.

However, and quite interestingly, while physical safety was a preoccupation for many parents, other aspects of safety, in particular the emotional one, seemed to be at the forefront of their concerns. It is important to note that the issue of safety in general was mentioned within the context of the larger issues that African Americans face in society. Indeed, insecurity, as seen by our homeschooling parents, is the predictable outcome of the white racism and white supremacy that they believe exist in America. Indeed, many of the parents with whom we spoke, shared the view that schools - public or private - could not, given the racist nature of American society, be safe for black children. Many refused to solely blame the children for engaging is school violence, but rather saw the physical lack of safety of schools as a reflection of the economically depressed black neighborhoods in which the children reside. Indeed, it is common for schools to mirror the conditions of the neighborhood in which they are located, creating an unfortunate synergy of school and neighborhood-related violence. Addressing the question of emotional, intellectual, and cultural safety, some parents squarely couched their analysis of racial school dynamics in war-like terms, with white schools and teachers described as the "enemy." Akira, whose children were never schooled, for example, is adamant: 
Why would I have my children instructed and taught by the enemy? I've always seen white teachers somewhat as the enemy, white school establishments, institutes, as the enemy. Why should I give my children to the enemy to be taught?

Similar sentiments are echoed by Richard, father of two, in Philadelphia:

I mean, the heart of the reason to me would be you don't allow an enemy to teach your child. We're allowing people who have historically oppressed us to educate our children, that is ridiculous, like that's foolish. Why would I allow my oppressor to teach my child who they are, who they're supposed to be?

Teachers' failure to provide an emotionally safe learning space for African American children was consistently mentioned and severely criticized. Parents, for instance, took issue with white teachers' hasty requests for cognitive testing of their children, sometimes after just a few days or weeks of school. They also described the disrespect that their children experienced on a daily basis, as proof of teachers' intent to make them uncomfortable and ultimately fail. Leticia, mother of four children, in Chicago, Illinois shared with us the following:

My daughter was probably in like, her 4th day of school ever, and I remember talking to her teacher and she said, "She can't do this, she can't do that, she can't do anything else," and I was like, "Excuse me? She is five! She's never been to school before in her life, what do you mean, "She can't do this, she can't do that"? What is she supposed to be, magic? Is she supposed to come to school already knowing everything? From then on, the teacher started calling her the "caboose" in the classroom.

In addition to the cruelty displayed by some teachers toward black children, many parents objected to the school's failure to provide their children with an intellectually and culturally safe space. Some noticed how questioning the invisibility of black achievements in society would simply not be tolerated by teachers. Kemet recalls how when, one day, her then second-grader son asked the white teacher why Benjamin Banneker, a distinguished African American architect, had not received any recognition for his accomplishments, he was severely punished:

He was suspended because he asked, he said, "Well, you know, Benjamin Banneker, he was a genius." And this white woman looked at him like, "What are you talking about? How dare you say something like that?" You know, she's teaching all these black children, a white woman, and he says, "People, why shouldn't they see him? At least put him on the dollar." And she suspended him.

Another father in Philadelphia, Chris, recalled how his son, while in $8^{\text {th }}$ grade, having been asked to write about one of his heroes, received an F for selecting Marcus Garvey. When confronted, the white male teacher argued that he did not know who Marcus Garvey was, and therefore he could not accept him as a legitimate choice. Yet, Marcus Garvey is held in the highest regard by large numbers of African people worldwide. The two instances cited above clearly represent a case of European intellectual and cultural intolerance, which in turn, denied black students a sense of intellectual and cultural safety. 
Furthermore, many parents resented the school's attempt not only to deny black children's right to be engaged in culturally meaningful interrogations and explorations, but also to impose whiteness as normative and ideal on their children. This, they felt, prevents their children from being themselves and from developing a positive racial and cultural identity. For Sia, the mother of six, in Philadelphia, Pennsylvania, the root of the problem is white ethnocentrism:

The white race, they are ethnocentric, that's all they are. It's all about them. That's what this country ... that's what they're all about.

The same mother further explained that she would not send her children to school because they might stop being black:

... they would go into the school and they would become assimilated, just like all the races. I call it the big machine. You have cultures that come here and they go through this machine... I would love to do a play on this one day ... and the machine is this western machine ... and it's the funniest thing when I see Korean children, girls, and they're walking down the hall or walking down the street with their white friends, and if you close your eyes, you can't tell who's who, and you open your eyes ... you can't tell because they're listening to the same music, they're wearing the same clothes. They take on the mannerisms, and they become, "white."

The same sentiment was echoed by Theresa, the mother of three, in Illinois, who remarked how:

... teachers and schools are not safe, they're going to take every chance they get to depersonalize you because they are not ... their concept of themselves is predicated on your lack of self, you know. So if you are yourself, they're threatened. So they're going to take every chance to put you down.

\section{Discussion and Summary}

The overall aim of this study was to gain insight into the experiences, views, and actions of African American parents who choose to educate their children at because of issues of safety commonly experienced in most schools. For the parents in this study being safe in school meant more than physical safety, but also included the emotional, intellectual and cultural security that one would expect in a 'safe' space where children can learn and thrive. Indeed, they yearn for an educational environment where their sons and daughters are encouraged to explore and ask questions freely so that they can make sense of the world as children of African descent. Instead the homeschooling parents in our study reported conditions where their sons or daughters had to endure palpable conditions of insecurity which made going to school an ordeal. Equally, if not more disturbing for parents, were teachers' inability to engage their children in a manner that acknowledges the historical and cultural experiences that African American students bring to the classroom.

African American parents were confounded at the lack of initiative taken by the school to address the cultural gap and discontinuity which exist between their children and the school curriculum (Allen \& Boykins, 1992; Delpit, 1995). This lacunae many parents felt contributed to 
an atmosphere of insecurity and danger in the school, and made possible the manifestation of insecurity outlined in this article: physical, emotional, and intellectual.

The lack of sensitivity in most public and private school curricula, added with the singular focus on Euro-American culture creates the notion of Whiteness as the natural norm. Indeed, the invisibility of Africa and African American history and culture in the curriculum has a de facto double effect. On one hand, it reinforces the racist assumption that Africa and people of African descent do not matter and are indeed inferior. On the other hand, it leads one to the no less racist conclusion that African people have not done anything worth mentioning, hence their omission in textbooks and classroom discussions. The concept of the "null" curriculum (Eisner, 1994), which refers to the powerful messages that the omission or reduction to footnote status of certain information conveys to students and teachers alike, is particularly relevant here. This by default curriculum, which chooses to ignore or marginalize the cultural and historical depth of African American children, is a pervasive and potent form of institutional racism. The devastating psychological impact of such a Eurocentric and racist perspective on the African American experience has been observed, and ranges from low self-esteem to outright self-hatred, and ultimately expressions of physical violence (Patton, Woolley, \& Hong, 2012; Thompkins, 2000).

In a provocative sense, the interviews illustrate the power of counter-storytelling as suggested by critical race theory. Counter storytelling affords the Black homeschooling parents to have their voices heard. A voice that has traditional been marginalized and rendered invisible both by the racist notion that African American parents are not involved in the schooling of their children and by the more publicized voice of white homeschooling parents. In accordance with the tenets of critical race theory, this study has demonstrated that (1) race is central to the experience of homeschooling African Americans, (2) the narrative of our subjects challenges the dominant ideologies that articulates the notion of color-blindness in the curriculum, where in fact the dominant and clear cultural orientation of most curricula is Euro-American, (3) black homeschooling parents have a great sense of self efficacy, agency, and social justice that leads to direct action to protect their children from insecurities of brick-and-mortar schools, and (4) through their private and public action to homeschool, African American parents give legitimacy to their experiential knowledge of the school system in America, which has largely been detrimental to children of African descent (Delgado \& Stefancic 2012; Ladson-Billings \& Tate 1995, Yosso, 2005)

Finally it is important to realize that the desire of African Americans to educate their children in the face of great physical and psychological trauma is nothing new. There exists a long history of sustained and heroic efforts on the part of African Americans to obtain education in the face of untold dangers. Many enslaved Africans, in their quest for a way out of slavery, did not hesitate to risk severe punishment, and sometimes even their lives, in order to learn to read and write (Anderson, 1988). During and after the Civil War, more than one thousand Sabbath schools, for example, were established in the South by formerly enslaved Africans for the purpose of making literacy available to adults and children. Later, in the midst of Jim Crow, African American parents actively organized to bring about the end of school segregation, with the implementation of Brown v. Board of Education. Thus, today, African American parents are increasingly taking upon themselves again to create better learning conditions for their children. This, they hope, will allow their children to maintain their love for learning and for themselves. 


\section{References}

Ahmed-Ullah, N. S. (June 26, 2012). Number of CPS students shot rises, as does fear of more to come, Chicago Tribune . Downloaded from http://articles.chicagotribune.com/2012-0626/news. March 31, 2013.

Allen, B. A., \& Boykin, A. W. (1992). African American children and the educational process: Alleviating cultural discontinuity through prescriptive pedagogy. School Psychology Review, 27(4), 586-596.

Anderson, J. (1988). The education of Blacks in the South, 1860-1935. Chapel Hill and London: The University of North Carolina Press.

Aud, S., Hussar, W., Kena, G., Bianco, K., Frohlich, L., Kemp, J. \& Tahan, K. (2011). The Condition of Education 2011 (NCES 2011-033). National Center for Education Statistics, Institute of Education Sciences, U.S. Department of Education. Washington, DC.

Becker, G. S. (1964). Human capital. New York: Columbia University Press.

Blum, Robert, W. (April, 2005). A case for School Connectedness. Educational Leadership, 62 (7), 16-20.

Corbin, J., \& Strauss, A. (2008). Basics of qualitative research: Techniques and procedures for developing grounded theory (3rd ed.). Thousand Oaks, CA: Sage.

Coleman, S. (2003). Home Schooling is Increasing among African Americans. In C. Mur (Ed.), Home Schooling At issue (pp. 22-25). San Diego: Greenhaven Press.

Collom, E. (2005). The ins and outs of homeschooling: The determinants of parental motivations and student achievement. Education and Urban Society, 37, 307-335.

Connell, J. P., \& Wellborn, J. G. (1991). Competence, autonomy, and relatedness: A motivational analysis of self-system processes. Self-processes and development. In M. R. Gunnar \& L. A. Sroufe (Eds.), Self processes and development. The Minnesota symposia on child psychology (Vol. 23, pp. 43-77). Hillsdale, NJ: Erlbaum.

Cornell, G. (2011) Myths about youth and violence and school safety. Virginia Youth Violence Project, Curry School of Education, University of Virginia. Retrieved from http://curry.virginia.edu/resource-library.

Delgado, R., \& Stefancic, J. (2012). Critical race theory: An introduction. NYU Press.

Delpit, L. (1995). Other people's children: Cultural conflict in the classroom. New York: The New Press.

Eisner, E.W. (1994). The educational imagination: On the design and evaluation of school programs. New York: MacMillan College Publishing Company.

Field-Smith, C. \& Williams, M. (2009). Motivations, sacrifices, and challenges: Black parents' decisions to homeschool. Urban Review, 41, 369-389.

Fitzpatrick, K. \& and Boldizar, J. P. (1993). The prevalence and consequences of exposure to violence among African-American Youth. Journal of the American Academy of Child \& Adolescent Psychiatry, 32(2), 424-430. 
Gathier, M. (2007). Homeschool: an American history. London: Palgrave McMillan.

Golafshani, N. (2003). Understanding reliability and validity in qualitative research. The Qualitative Report, 8, 597-607.

Grady, S., \& Bielick, S. (2010). Trends in the use of school choice 1993 to 2007. (NCES 2010004). National Center for Education Statistics, Institute of Education Sciences, U.S. Department of Education. Washington, DC. Retrieved from http://nces.ed.gov/pubs2010/2010004.pdf

Green, C. L., \& Hoover-Dempsey, K. V. (2007). Why do parents home-school? A systematic examination of parental involvement. Education \& Urban Society, 39, 264-285.

Haney, K. (October 13, 1999). All City High Schools to Receive Metal Detectors. Retrieved from http://articles.philly.com/1999-10-13/news.

Isenberg, E.J. (2007). What have we learned about homeschooling? Peabody Journal of Education, 82, 2/3, 387-409.

Janson, G. R. and King, M. A. (April 2006). Emotional Security in the Classroom: What works for young children. Journal of family and consumer sciences, 98 (2): 70-74.

Kirk, J. A., (2002). Redefining the Color Line: Black Activism in Little Rock, Arkansas, 1940-1970. University of Florida Press.

Kozol, J. (2005). The shame of the nation: the restoration of apartheid schooling in America. New York: Random House.

Ladson-Billings, G. (1995). Toward a theory of culturally relevant pedagogy. American Educational Research Journal, 32(2), 465-491.

Leach, S. (March 26, 2013). Metal detectors a possibility for city elementary schools? Retrieved from http://articles.philly.com/2013-03-26/news.

Manvell, E. C. (2012). The violence continuum: creating a safe school climate. Maryland: Rowman \& Littlefield Publishers, Inc.

Mazama, A. (Ed.). (2003). The Afrocentric paradigm. Trenton: Africa World Press.

McDowell, S., Sanchez, A. \& Jones, S. (2000). Participation and perception: Looking at homeschooling through a multicultural lens. Peabody Journal of Education, 75 (1 \& 2), 124-146.Noddings, Nel (2007). When School Reform Goes Wrong. New York: Teachers College Press.

Merrow, J. (2004). Safety and excellence. Education Horizon, 83 (1), 19 - 32.

Murrell, P. (2002). African-centered pedagogy: Developing schools of achievement for African American children. Albany: State University of New York Press.

NYCLU Report. (2010). School to prison pipeline. Retrieved from http://www.nyclu.org/issues/youth-and-student-rights/school-prison-pipeline.

Ozer, E. J. (2005). The impact of violence on urban adolescents: Longitudinal effects of perceived school connection and family support. Journal of Adolescent Research, 20(2), 167-192.

Patrone, N. (March/April 2007). Emotional Support and Student Learning. Principal. Retrieved from http://www.naesp.org

Patton, D. U., Woolley, M. E., \& Hong, J. S. (2012). Exposure to violence, student fear, and low academic achievement: African American males in the critical transition to high school. Children and Youth Services Review, 34, 388-395.

Ray, B. (2010). Academic achievement and demographic traits of homeschool students: A nationwide study. Academic Leadership Journal, 8(1), 1p. Retrieved from http://contentcat.fhsu.edu/cdm/compoundobject/collection/p15732coll4/id/456. 
Reyes, M. R., Brackett, M. A., Rivers, S. E., White, M., \& Salovey, P. (2012). Classroom emotional climate, student engagement, and academic achievement. Journal of Educational Psychology, 104(3), 700-712.

Robers, S., Zhang, J., and Truman, J. (2012). Indicators of School Crime and Safety: 2011 (NCES 2012-002/NCJ 236021). National Center for Education Statistics, U.S. Department of Education, and Bureau of Justice Statistics, Office of Justice Programs, U.S. Department of Justice. Washington, DC. Retrieved from http://www.bjs.gov

Skiba, R. J., Simmons, A. D., Ritter, S., Gibb, A., Rausch, M. K., Cuadrado, J., \& Chung, C. G. (2008). Achieving equity in special education: History, status, and current challenges. Exceptional Children, 74, 264-288.

Sylwester, R. (1994). How emotions affect learning. Educational Leadership, 52(2), 60-65.

Taylor, V. (2005). Behind the trend: Increases in homeschooling among African Americans families. In B. Cooper (Ed.). Home schooling in full view. A reader. Information Age Publishing, Inc. (pp. 121-134).

Thompkins, D. (2000). School violence: Gangs and a culture of fear. Annals of the American Academy of Political and Social Science, 567, 54-71.

Van Galen, J. (1991). Ideologues and pedagogues : Parents who teach their children at home. In J. Van Galen \& M. Pittman (Eds), Homeschooling : Political, historical and pedagogical perspectives (pp. 67-92). Norwood, New Jersey : Ablex.

Wilson, W. J. (1996). When Work Disappears: The World of the New Urban Poor. New York, NY: Vintage Books.

Yosso, T. J. (2005). Whose culture has capital? A critical race theory discussion of community cultural wealth. Race Ethnicity and Education, 8(1), 69-91. 